\title{
The transition process towards the yellow ball in tennis teaching
}

\section{Caio Corrêa Cortela ${ }^{\text {a }}$ (D) , Juan Pedro Fuentes García $\mathbb{1}^{\text {b }}$, Michael Davis Higuera ${ }^{\text {c }}$ \& Layla Maria Campos Aburachid ${ }^{\mathrm{d}}$}

${ }^{a}$ Paranaense Tennis Federation, Curitiba, Brazil. ${ }^{b}$ University of Extremadura, Badajoz, Spain. ${ }^{\mathrm{c}}$ Tennis Development, Integrity and Development Department, International Tennis Federation, London, UK. ${ }^{d}$ Federal University of Mato Grosso, Cuiabá, Mato Grosso, Brazil.

\section{ABSTRACT}

More than 10 years have gone by since Play and Stay campaign was launched, and even today, there is a lack of scientific studies focusing their strategies on the transition process between the stages that make up Tennis 10s. So, on the basis of interviews with expert coordinators, who are responsible for sport initiation programmes in Brazilian clubs, this study tries to describe the strategies used for the transition between the "green ball" and the "yellow ball".
Key words: tennis, sport initiation, competition, Tennis 10 s.

Received: 16 June 2019

Accepted: 24 September 2019

Corresponding author: Caio

Corrêa Cortela, Paranaense

Tennis Federation, R. Pastor Manoel Virgínio de Souza, 1020

- Capão da Imbuia, Curitiba PR, 82810-400, Brazil. Email: capacitacao@cbtenis.com.br

\section{INTRODUCTION}

The use of low pressure yellow balls is considered by the International Tennis Federation as a key aspect in the sport initiation process (Miley, 2010). According to Newman (2010), the slower balls provide more time for the response, facilitate the learner's return and help to develop and adopt more advanced tactical-technical patterns used in competitive tennis, and will be useful in the future to reach top performance.

Studies that involve adapted materials have provided favourable evidence of the use of structural adaptations in children's tennis (Buszard et al., 2016). In situations of stroke tests, Buszard et al. (2014), reported a positive impact in the performance of the forehand in those kids who were using materials and balls adapted to their age groups; when compared to those using conventional materials, the first ones showed greater efficiency and efficacy in stroke and movement pattern performance. Likewise, Larson \& Guggenheimer (2013) described tennis players whose strokes were tested in adapted conditions (orange stage), if compared with the results using conventional courts and balls, the results were significantly better, hitting with greater speed and accuracy and with a higher degree of efficacy.

In the learning situation, Farrow \& Reid (2010) reported similar results to those observed during the tests, confirmed that the kids exposed to adult playing conditions had less learning opportunities, hit less balls per training session, were less successful in stroke production and were less motivated to continue playing tennis.

During matches and/or competitions, it was shown that constraints derived from the use of adapted material had a positive effect on players' behaviour. Thus, Fitzpatrick et al. (2017) showed that matches played in adapted conditions (Red and Orange Stage) favoured longer rallies. Schmidhofer et al. (2014) declared that matches played in Orange Stage of Tennis 10 s, were the closest to professional tennis in the number of points won at the net and the rhythm of stroke execution. Kachel et al. (2014) said that the use of the green balls, instead of yellow balls, encouraged changes in the playing patterns that kids adopted, and made them more aggressive when using the green balls, going to the net and rallying with faster strokes and hitting more strokes inside their comfort zone. 
In spite of the increasing research to understand the impact of structural and methodological adaptations in kid's learning/ training process, little is known about the influence of practice structures and the use of adapted materials in the progression process for kids in the different stages of Tennis 10s (Buzard et al., 2018).

According to the constraint based approach, when adapting the material to the game, you change the interaction of three types of factors or constraints (individual, environmental and task) and, thus, the action and the potential for action change as well (Davids et al., 2008). In this case, using slower and lower bouncing balls, children can adapt their techniques and tactics to their skills and capabilities by means of a divergent discovery or learning process. This can be a starting point to understand when to pass from one Tennis 10s stage to the next one: players must do so when their capabilities let them start learning skills that represent the competitive level of the game, when they already know the patterns and /or can execute them as if they had a playing style similar to that of the competitive level: this means they are already competent in the previous level.

Thus, the transition in the ball use is a key point in the sport initiation process, especially when passing from the Green ball (25\% slower) to the Yellow ball. A bad transition at this stage would put the work of the previous stages at risk, producing unwanted adaptations in the basic tactical/ technical fundamentals. Considering the scenario above, the aim of this study has been to describe the transition process from the Green ball to the Yellow ball in Brazilian clubs.

\section{METHODS}

The sample for this study consisted of 14 coordinators from Brazilian clubs, prestigious in sport initiation and tennis player development. The professionals that were interviewed had previous experience in regional level (7), national level (4) and international level (3) tennis players, and an average coaching experience of $23,8 \pm 11,8$ years.

At the time of gathering data, the clubs analysed had 2,980 students involved in sport initiation programmes (not introduced to the use of the yellow ball yet). Most programmes started with kids of approximately 5 years old, and finished the participation in Green Stage at the age of 10.

Categorization of the findings was made by Sparkes and Smith (2014) "theme analysis" , considering for the analysis and comments all the units that grouped the responses of three or more coordinators.

\section{FINDINGS AND DISCUSSION}

In Figure 1, we present a single category in which at least three coordinators reached consensus.
Table 1. Strategies for the transition from the green to the yellow ball

\begin{tabular}{ll}
\hline Coordinators & Category \\
\hline (U6; U12;U13) & $\begin{array}{l}\text { Using the green and the yellow balls } \\
\text { simultaneously in the sessions. }\end{array}$
\end{tabular}

[...] coaches use them more often towards the end of the year. Coaches start using the balls, mixing them. [...] as of the end of September. In January, they will be playing (this means only yellow balls). (S12 - 70'52").

Although some coordinators adopted a specific procedure for the transition, it was impossible to identify clearly that their transition process had happened in a non systematic way, and empirically, without well defined criteria for the process (time of intervention, time of use destined to using each type of ball in the session, structure of the practice...)

[...] I think it has to be natural. The main point coaches have expressed is that the coach has to observe and be very alert with this change. I don't have a very organized project yet, I cannot say "we are systematized, we are doing it this way"that does not exist so far. What we do have today is a process.... In fact it consists of a different attention to those kids in the transition stage. Mainly the grip and the height of the impact point. (S5-47'28').

The "clinical eye" of the coach seems to be the main parameter to determine how and how fast to make the transition. According to the coordinators, the height of the impact point between the racket and the ball and the grip used were the reference criterion for the coach to observe. These two factors are just the most impacted by the use of the Green ball, which according to Kachel et al. (2015) and Newman (2010), and on the basis of the constraint based theory (Davids et al., 2008), enable impact points that are much more appropriate for kids, due to the material the balls are made of, which allows the optimization of the adaptation to the height of the children in this stage.

Just as expressed by Buszard et al. (2018), competition demonstrated that it plays an important role at the beginning of the transition between balls/stages. Four coordinators stated that this process started some months before the end of the year of competitions, so it was possible for children to adapt and compete with the yellow ball in the Summer tours at the beginning of the new season. "Guga Cup", one of the most important competitions in the country, was mentioned by two coordinators as being the last one with adapted balls and the beginning of the transition process towards the yellow ball.

These findings strengthen the role of the competitive system in the training programmes, from the first stages of sport preparation to the long term,(Gonçalves et al., 2016). Thus, it is necessary to analyse the pros and cons of extending the use of the Green ball in a regular way in competitions until older ages. This modification could reduce the impact of the 
transition, particularly regarding the contact point and grip change, depending on the height and strength of the kids.

\section{CONCLUSIONS}

Given the lack of research about transition between stages in ITF Tennis 10s, we suggest basing the studies on the impact of the different practice conditions, especially in the combinations of different materials (green and yellow balls), by means of variability in the practice using different instruments, implements and materials (weight, size, textures...). All of the above, in order to get in the transition phase, the best learning results in acquisition, retention and transference.

Given the identification of the coach's "clinical eye" and the importance of certain playing factors like grip and height of the impact point for the transition to the next stage, and given an understanding of the constraint based approach, we find it important to start analysing systematically all the factors that may serve to predict good performance in the next stage, so as to set guidelines for the transition between stages not based on age but on capability. This could result in a better participation and skill acquisition rate and a lower rate of dropping out at developing ages.

Note: the authors would like to acknowledge the financial and logistic support of the Brazilian Tennis Confederation for the development of this study.

\section{REFERENCES}

Buszard, T., Farrow, D., Reid, M. \& Masters, R. (2014). Modifying equipment in early skill development - a tennis perspective. Research Quarterly for Exercise and Sport, 85(2), 218-225, https://doi.org/10.1080/02701367.2014.893054

Buszard, T., Reid, M., Masters, R. \& Farrow, D. (2016). Scaling the Equipment and Play Area in Children's Sport to improve Motor Skill Acquisition: A Systematic Review. Sports Med. 46(6), 829-843, https://doi.org/10.1007/s40279-015-0452-2

Buszard, T., Farrrow, D. \& Westerbeek, H. (2018). Evaluation of the ITF Tennis Play and Stay campaing since its inception in 2007. Nieuwegein: Arko Sports Media.

Davids, K., Button, C. and Bennett, S. (2008). Dynamics of skill acquisition: a constraints-led approach. Leeds; Champaign, II: Human Kinetics.

Farrow, D. \& Reid. M. (2010). The effect of equipment scaling on the skill acquisition of beginning tennis players. Journal of

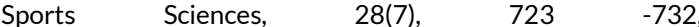
https://doi.org/10.1080/02640411003770238

Fitzpatrick, A., Davids, K. \& Stone, J.A. (2017). Effects of Lawn Tennis Association mini tennis as task constraints on children's match-play characteristics. Journal of Sports Sciences, 35(22), 2204-2210, https://doi.org/10.1080/02640414.2016.1261179

Goncalves, G.H.T., Cortela, C.C., Klering, R.T., Bulso, R. \& Balbinotti, C.A.A. (2016). The role of the tennis competition for children on the basic technical and tactical fundaments development. Conexões, 14(2), 30-52, https://doi.org/10.20396/conex.v14i2.8646012
Kachel, K., Buszard, T. \& Reid, M. (2015). The effect of ball compression on the match-play characteristics of elite junior tennis players, Journal of Sports Sciences, 33:3, 320-326, DOI: 10.1080/02640414.2014.942683

Larson, E. J. \& Guggenheimer J. D. (2013). The Effects of Scaling Tennis Equipment on the Forehand Groundstroke Performance of Children. Journal of Sports Science and Medicine, 12, 323-331, https://doi.org/10.1080/02640414.2014.942683

Miley, D. (2010). Serve rally and score: the ITF tennis play and stay campaign and tennis 10s. Coaching and Sport Science Review, 51, 3-5.

Newman, J. (2010). Why slower balls and smaller courts for 10 and under players? Coaching and Sport Science Review, 51, 57.

Schmidhofer, S., Leser, R. \& Ebert M. (2014). A comparison between the structure in elite tennis and kids tennis on scaled courts (Tennis 10s). International Journal of Performance Analysis in Sport, 14(3), 829-840, https://doi.org/10.1080/24748668.2014.11868761

Sparkes, A.C. \& Smith, B. (2014). Qualitative research methods in Sport, Exercise and Health. London: Routledge, https://doi.org/10.4324/9780203852187

RECOMMENDED ITF TENNIS ACADEMY CONTENT (CLICK BELOW)

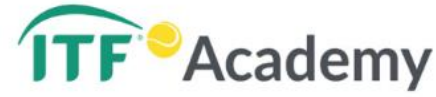

Copyright (c) 2019 Caio Corrêa Cortela, Juan Pedro Fuentes García, Michael Davis Higuera \& Layla Maria Campos Aburachid

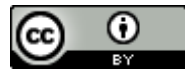

This text is under a Creative Commons BY 4.0 license

You are free to Share - copy and redistribute the material in any medium or format - and Adapt the content - remix, transform, and build upon the material for any purpose, even commercially under the following terms:

Attribution: You must give appropriate credit, provide a link to the license, and indicate if changes were made. You may do so in any reasonable manner, but not in any way that suggests the licensor endorses you or your use.

CCBY4.0license terms summary CCBY4.0license terms 